\title{
Return to Sports after Lower Extremity Injuries: Assessment of Movement Quality
}

\author{
Christiane Wilke' ${ }^{1}$ Lucie Pfeiffer ${ }^{2}$, Ingo Froböse ${ }^{1}$ \\ ${ }^{1}$ Institute of Health Promotion and Clinical Movement Science, German Sport University Cologne, Cologne, Germany \\ ${ }^{2}$ Birkle-Clinic, Überlingen, Germany \\ Email: wilke@dshs-koeln.de
}

How to cite this paper: Wilke, C., Pfeiffer, L. and Froböse, I. (2017) Return to Sports after Lower Extremity Injuries: Assessment of Movement Quality. Health, 9, 1416-1426. https://doi.org/10.4236/health.2017.910104

Received: April 12, 2017

Accepted: September 26, 2017

Published: September 29, 2017

Copyright (c) 2017 by authors and Scientific Research Publishing Inc. This work is licensed under the Creative Commons Attribution International License (CC BY 4.0).

http://creativecommons.org/licenses/by/4.0/

\begin{abstract}
Numerous high performance athletes experience further damage or recurrent injuries even after successful rehabilitation. This is often caused by an insufficient movement quality, which has been very rarely assessed by test protocols which determine the point of reintegration into high performance sports (Return-to-Play, RTP). In order to assess the movement quality both objective and subjective test protocols exist. Objective methods like 3D-movement analysis are viewed as international gold standard, but are not the most practicable solutions for daily training routine. This study aims at reviewing the available literature on reliability and validity of existing subjective test protocols. Further their use within high-performance sports is evaluated. Up to now subjective methods fail to match sufficient validity. However some practical approaches for assessment of movement quality after injury are known. Based on selected criteria first recommendations for the use of different subjective screening test methods are given. In summary further research focusing on the validity of subjective tests is needed. The subjective testing methods should be used in combination with additional tests (e.g. strength testing) in order to identify other risk factors. Recurrent pre-injury screenings on movement quality should be carried out to enhance injury prevention.
\end{abstract}

\section{Keywords}

Lower Extremity, Injury, Movement Quality, Subjective Assessment

\section{Introduction}

Despite successfully completed rehabilitation after injury numerous high performance athletes still suffer recurrent injuries [1]. Hagglund et al. conducted a prospective study in elite football players and identified a two to three times 
higher re-injury risk after hamstring injury, groin injury and knee joint trauma. Recent reviews suggest higher rates of recurrence and contralateral injuries after anterior cruciate ligament (ACL) rupture as well as injuries of the hamstring and ankle joint [2] [3]. Besides a high risk of recurrent injury, the risk of suffering from overuse by synovitis and osteoarthritis is increasing after ACL injury. This results in early drop-outs of some athletes or an unsuccessful comeback. The current high rates of reinjured athletes are caused by functional deficits like insufficient neuromuscular control and stability [4] [5] [6]. After rehabilitation of lower extremity injuries primarily the aspects of strength, proprioception, symmetries and neuromuscular control as well as static and dynamic stability are not sufficiently developed. This impacts the kinematics as well as the motor control both distal and proximal of the injury and increases the reinjury-risk [3]. However these aspects are not considered to determine the point of time for a Return-to-Play. Decisions are made by looking at predictive healing periods or single tests like the comparison of the isokinetic force of the injured and non-injured extremity [5] [7]. Barely any objective criteria exist in order to ensure a safe and long-term rehabilitation and re-integration into high performance sport for the injured athlete. One of the most important factors which need to be considered when looking at the time for a RTP is the movement quality. In most patients the movement quality is reduced considerably after injury which leads to an increasing risk of reinjury. Insufficient movement quality comes with deviation in movement axis during dynamic movements, non-functional partial movements, or high impact landings [8] [9]. As a foundation towards specific therapeutic movement training the testing of movement quality should be conducted. Until now almost no standardized test for assessing movement quality is established in order to ensure a safe rehabilitation and re-integration into high performance sports by objective criteria.

\section{Testing Methods}

A literature research was carried out in the databases PubMed, MEDLINE, Google Scholar, SPOLIT and EMBASE from March until June 2015. Only available research articles, systematic reviews and scientific commentaries in English were considered. No restrictions on publication date were made within the literature research. Following keywords were used for movement quality: movement, move, moving, and coordination in combination with quality, pattern, competency, characteristics and criteria. To identify subjective measures for assessing movement quality following keywords were used: motion analysis, assessment, screening, test and grading. For integrating specific testing measures the keywords motion capture, kinematics, kinetics, visual rating, observation, neuromuscular screening, electromyography, force plate and biomechanical analysis were used. If specific measures were identified, the keywords validity and reliability were added to the search. Functional testing, performance test and task were used additionally to search for sport-specific methods. Further the 
keywords athletes, competitive sport, serious sports, sports and performance were used to identify suitable tests for high performance sports. Moreover return to sports, return to play, return criteria, sport criteria, sports participation, reintegration as well as rehabilitation and prevention were used for the aspect of reintegration. To identify articles covering injury-related topics injury and ACL were used. Findings were then compared and analysed in order to identify standardised and feasible assessment methods for movement quality. Because of feasibility only subjective testing methods without any technical or device-related requirements were included. An overview of selected methods is given in Table 1. The judging criteria of the mentioned tests are based on biomechanical risk factors and injury mechanisms of the lower extremity, in particular for ACL-injuries.

Table 1. Subjective tests for assessing movement quality-testing measures.

\begin{tabular}{|c|c|c|c|}
\hline Testing method & Functional tests & Assessment criteria & Scaling \\
\hline FMS & $\begin{array}{l}\text {-Deep Squat } \\
\text {-Hurdle Step } \\
\text {-In Line Lunge } \\
\text {-Shoulder Mobility } \\
\text {-Active Straight Leg Raise } \\
\text {-Trunk Stability Push Up } \\
\text {-Rotary Stability }\end{array}$ & $\begin{array}{l}\text {-Alignment of shoulder, trunk, lumbar } \\
\text { spine, hip, femur, knee, ankle joint } \\
\text {-Balance } \\
\text {-ROM }\end{array}$ & $\begin{array}{l}\text { Categorical: } \\
0 \text { Pain } \\
\text { 1) Not possible } \\
\text { 2) Compensating } \\
\text { 3) Correct }\end{array}$ \\
\hline AAA & $\begin{array}{l}\text {-Prone Hold } \\
\text {-Lateral Hold } \\
\text {-Overhead squat with } 10 \mathrm{~kg} \\
\text {-SLS off box } \\
\text {-Walking Lunge with } 20 \mathrm{~kg} \\
\text {-Single Leg Forward Hop } \\
\text {-Lateral Bound } \\
\text {-Push Ups } \\
\text {-Chin Ups }\end{array}$ & $\begin{array}{l}\text {-Alignment of shoulder, hands, trunk, } \\
\text { hip, knee ankle joint } \\
\text {-Rhythm, control, landing } \\
\text {-Time, depth, rep }\end{array}$ & $\begin{array}{l}\text { Categorical: } \\
\text { 1) Not possible } \\
\text { 2) Compensation } \\
\text { 3) Correct }\end{array}$ \\
\hline LESS + Sl-LESS & $\begin{array}{l}-\mathrm{DVJ} \\
-\mathrm{SLDVJ}\end{array}$ & $\begin{array}{l}\text {-Alignment of trunk, hip, knee, foot } \\
\text {-General impression }\end{array}$ & $\begin{array}{c}\text { Dichotomous: } \\
0 \text { No error } \\
1 \text { Error } \\
\text { (item } 16,17 \text { categorical) }\end{array}$ \\
\hline QASLS & $\begin{array}{l}-S L S \\
-S L L\end{array}$ & $\begin{array}{l}\text {-Alignment of arm, trunk, pelvis, thigh, } \\
\text { knee } \\
\text {-Unsteady standing }\end{array}$ & $\begin{array}{l}\text { Dichotomous: } \\
0 \text { No deviation } \\
1 \text { Deviation }\end{array}$ \\
\hline TJA & -Tuck Jump & $\begin{array}{l}\text {-Alignment of knee, thigh, foot } \\
\text {-Plyometric technique (loud, pausing, } \\
\text { maintenance) }\end{array}$ & $\begin{array}{l}\text { Dichotomous: } \\
0 \text { No deviation } \\
1 \text { Deviation }\end{array}$ \\
\hline VST + VHST & $\begin{array}{l}\text {-SLS } \\
\text {-sw jumps } \\
\text {-fw/bw jogging } \\
\text {-VHST: instead of fw/ww jogging, } \\
\text { diagonal jumps and fw lunges on box }\end{array}$ & $\begin{array}{l}\text {-Alignment of trunk and knee } \\
\text {-Short landing phase } \\
\text {-VHST: +hip }\end{array}$ & $\begin{array}{l}\text { Dichotomous: } \\
0 \text { Deviation } \\
1 \text { Correct }\end{array}$ \\
\hline
\end{tabular}

FMS: Functional Movement Screen; AAA: Athletic Ability Assessment; LESS: Landing Error Scoring System; QASLS: Qualitative Analysis of Single Leg Loading; TJA: Tuck Jump Assessment; VST: Vail Sport Test; VHST: Vail Hip Sport Test; DVJ: Drop Vertical Jump; SLDVJ: Single Leg DVJ; SLS: Single Leg Squat; SLL: Single Leg Landing; sw: sideways; fw: frontwards; bw: backwards; rep: repetitions. 
Almost no tests for assessing movement quality of the upper extremity are available. Movement quality is assessed during the athletes performing different functional tests. The rating is based on selected criteria related to certain scoring points. Depending on the sum of the scoring points the test is successfully completed and the athlete is ready for the specified level of rehabilitation.

Table 1 shows the specific testing measures of the selected subjective tests for assessing the movement quality. The most known and reviewed screening test is the Functional Movement Screen (FMS). As a further development of the FMS the Athletic Ability Assessment (AAA) aims at high performance sports. The Landing Error Scoring System (LESS) is already used in practice and relatively well known. The Qualitative Analysis of Single Leg Loading (QASLS) is less known and assesses the movement quality during single leg movements only. Another test for assessing the movement quality is the Tuck Jump Assessment (TJA). This simple assessment method is often used in combination with other screening tools. Ultimately the Vail Sport Test (VST) and its specific version for hip injuries, the Vail Hip Sport Test (VHST) is available.

\section{Quality Criteria}

An overview of studies on reliability, validity and objectivity of the selected tests is shown in Table 2. It shows clearly that none of the selected tests is explicitly validated yet. This is due to an insufficient number of studies on quality criteria of the mentioned testing methods. Due to the nature of subjective testing on the basis of movement observations it is challenging to fulfill quality criteria in an optimal way. Assessment criteria were developed in order to be able to give

Table 2. Quality criteria of subjective series of tests on movement quality.

\begin{tabular}{|c|c|c|c|}
\hline $\begin{array}{l}\text { Testing } \\
\text { method }\end{array}$ & Validity & Reliability & Objectivity \\
\hline FMS & $\begin{array}{l}\text {-predictive validity* not given }[10][11] \\
\text {-predictive validity partially given }[12] \\
\text {-predictive validity given }[13] \\
\text {-internal and external criterion } \\
\text { validity not given }[13]\end{array}$ & $\begin{array}{l}\text {-acceptable }[12][14] \\
\text {-good }[15] \\
\text {-excellent }[13]\end{array}$ & $\begin{array}{l}\text {-acceptable }[12][14] \\
\text {-excellent }[13]\end{array}$ \\
\hline AAA & n.a. & $-\operatorname{good}[16]$ & $-\operatorname{good}[16]$ \\
\hline LESS & $\begin{array}{l}\text {-internal criterion validity given [17] } \\
\text {-predictive validity not given [18] } \\
\text {-predictive validity given [19] }\end{array}$ & $\begin{array}{l}\text {-good [20] } \\
\text {-excellent }[18]\end{array}$ & $\begin{array}{l}\text {-moderate }[20] \\
\text {-good }[21] \\
\text {-excellent }[17][18]\end{array}$ \\
\hline QASLS & $\begin{array}{l}\text {-internal criterion validity given [22] } \\
\text {-content validity given [23] }\end{array}$ & $\begin{array}{l}\text {-very good to } \\
\text { excellent [23] }\end{array}$ & $\begin{array}{l}\text {-good to excel-lent } \\
{[23]}\end{array}$ \\
\hline TJA & -content validity probably given [24] & $\begin{array}{l}\text {-acceptable }[25] \\
\text {-very good to } \\
\text { excellent }[26]\end{array}$ & $\begin{array}{l}\text {-very good to } \\
\text { excellent [26] }\end{array}$ \\
\hline \multicolumn{2}{|c|}{ VST + VHST n.a. } & -excellent [27] & -excellent [27] \\
\hline
\end{tabular}

FMS: Functional Movement Screen; AAA: Athletic Ability Assessment; LESS: Landing Error Scoring System; QASLS: Qualitative Analysis of Single Leg Loading; TJA: Tuck Jump Assessment; VST: Vail Sport Test; VHST: Vail Hip Sport Test; ${ }^{*}$ predictive validity regarding injuries of lower extremity. 
recommendations concerning the use of the tests and to verify the quality criteria. These criteria are based upon quality criteria such as efficiency, utility and scaling of the tests. There for the screening methods were analyzed towards the suitability and applicability of tests and sub-tests in high performance sports, practicability and prevention of further injuries.

The screening methods should include an unsophisticated test design as well as simple scoring rules with only few items and easy scale of assessment (e.g. dichotomous).

The test design must reflect the complexity of requirements in high performance sports though. Therefore the type of functional testing within the tests is assessed. The test should include different unilateral, bi-lateral and high intensity functional tests in order to create comparable physical demands like the specific sport.

At the same time the series of tests should integrate well observable movement tasks for improving reliability and objectivity.

The used criteria for assessing movement quality are also relevant to ensure a safe rehabilitation/reintegration into high performance sport. If possible these criteria should be based on risk factors and mechanisms of sports injuries (e.g. valgus degree of deformity during landing [28] [29]). Table 3 gives an overview on the fulfillment of selected criteria of the different testing methods.

\section{Recommendations for Use of Testing Methods}

No explicit recommendation can be given for any of the subjective testing methods for assessing the movement quality. This is due to a small amount of scientific research on some tests and contradictory results on the validity of others. Based on the mentioned quality criteria advices for the use of subjective tests and first possibilities for the assessment of movement quality within the scope of rehabilitation shall be given.

Although recent studies verified the FMS' reliability and objectivity [12] [13] [14] [15] it cannot be recommended for the assessment of high performance athletes because of the insufficient physical demands of the functional tests included in the FMS. In order to use the FMS in high performance sports a combination with further and physically demanding tests like the TJA can be considered. The current design of the FMS is suitable for non-elite athletes as well as health and fitness athletes performing sports with submaximal load.

The AAA is a result of further development of the FMS [16]. It contains different functional tests which are comparatively physically demanding but still good for monitoring. The addition of maximal plyometric jumps, for example tuck jumps (the athlete jumps for 10 seconds with the knees at hip height each time) should be considered. Disadvantage of the AAA is the complex evaluation sheet due to the versatile functional tests included. Since the AAA is a newly developed tool, further research can redevelop simplified versions. The AAA is recommended conditionally with only one study analyzing the AAA, however showing good reliability and objectivity [16]. 
Table 3. Comparison of different criteria and recommendation for subjective test procedures on movement quality.

\begin{tabular}{|c|c|c|c|c|c|c|}
\hline \multirow[b]{2}{*}{ Criterion } & \multicolumn{6}{|c|}{ Testing method } \\
\hline & FMS & AAA & LESS & QASLS & TJA & $\begin{array}{l}\text { VST/ } \\
\text { VHST }\end{array}$ \\
\hline FT well observable & + & + & - & 0 & - & + \\
\hline FT demanding & - & + & + & 0 & + & + \\
\hline $\begin{array}{l}\text { FT maximally } \\
\text { demanding }\end{array}$ & - & - & + & 0 & + & - \\
\hline Multiple FT & + & + & + & 0 & - & + \\
\hline Unilateral FT & + & + & + & + & - & + \\
\hline Bilateral FT & + & + & + & - & + & + \\
\hline FT including resistance & - & + & - & - & - & + \\
\hline FT at exhaustion & - & + & - & 0 & + & + \\
\hline $\begin{array}{l}\text { Importang RF in } \\
\text { assessment criteria }\end{array}$ & + & + & + & - & + & - \\
\hline Simple scoring & - & - & 0 & + & + & 0 \\
\hline $\begin{array}{l}\text { Phases of motion } \\
\text { included }\end{array}$ & - & - & + & - & - & + \\
\hline Dichotomous scale & - & - & + & + & + & + \\
\hline OE included & + & + & - & - & - & - \\
\hline $\begin{array}{l}\text { Assessed by multiple } \\
\text { studies }\end{array}$ & + & - & + & - & $0 /+$ & - \\
\hline Reliable & $0 /+$ & $0 /+$ & + & $0 /+$ & $0 /+$ & $0 /+$ \\
\hline Valid & 0 & - & $0 /+$ & 0 & 0 & - \\
\hline Recommendation & - & $0 /+$ & $0 /+$ & 0 & 0 & 0 \\
\hline
\end{tabular}

FMS: Functional Movement Screen; AAA: Athletic Ability Assessment; LESS: Landing Error Scoring System; QASLS: Qualitative Analysis of Single Leg Loading; TJA: Tuck Jump Assessment; VST: Vail Sport Test; VHST: Vail Hip Sport Test; FT: functional test(s); RF: risk factors; UE: upper extremity; ${ }^{\star}$ FT at exhaustion only included with minimum of 10 reps or 10s each try; - (minus): not available/no; 0: partially available/given; + (plus): available/yes.

The new developed SL-LESS integrates unilateral as well as bilateral functional tests and can be recommended conditionally. The included tests are difficult to monitor and only assess jumping movements. Though the DVJ and SLDVJ require maximal effort and therefore reflect and match the requirements of high performance sports. The inner criteria validity of the LESS could be shown in two studies on 2710 athletes [17] [21]. The predictive validity shows contradictorily results [18] [19]. The LESS and SL-LESS can be used in combination with further tests which include well monitored movement tasks.

The QASLS can be used to assess single-leg squats as well as complex single-leg landings though no bi-lateral movement tasks can be conducted. Only two pilot studies have analyzed the QASLS so far [22] [23]. Therefore the QASLS can only be recommended conditionally. The QASLS includes a simple evaluation scale within a maximum of two functional tests. This small scale test is ap- 
plicable for preliminary assessment when only limited time is available. In late rehabilitation phase the TJA could be performed additionally [22]. The TJA only assesses bilateral jumps. As the TJA includes maximally exertion and repeated testing, which allows the assessment of movement quality under physical fatigue, the test becomes difficult to monitor. Even though the TJA has been developed more than 10 years ago [26], only a small amount of studies have analyzed the TJA so far. As a consequence the TJA can only be partly recommended as a preliminary assessment and additional test with a simple evaluation sheet [24] [30].

Further test tools for the evaluation of the movement quality by subjective monitoring are the VST and VHST. These include functional tests in all directions of movement which are both suitable for monitoring and as well physically demanding due to the length of the test. However movement tasks with maxi-mal load and analysis of single risk factors (e.g. no assessment of ankle joint) are missing. Though some scientific research on the VST and VHST is available [31] [32] [33] only one experimental study on the VST has been conducted, showing excellent reliability [27]. Based on these aspects, the LESS and AAA can be recommended conditionally. A refined depiction of selected tests and associated compliance with listed criteria is given in Table 3.

\section{Objectification and Supplementation of Testing Methods}

The selected and described tests are subjective tests only. Compared to objective methods these subjective tests are practicable as well as efficient in terms of time and budget. The existing subjective tests can be additionally enhanced by objective measures to increase precision, validity and reliability. 3D movement analysis qualifies as gold standard for objectifying movements, however they are very elaborate. Even the use of 2D video recording (e.g. using a mobile phone) already enhances the possibility and quality of an assessment. Slow-motion functions and repeated viewing facilitate a detailed assessment even with frequent and fast movements. Recorded videos can be used for comparison later on. Another possibility is the use of straight lines and angles within snapshots (e.g. Valgus angle) by using video technology, which can increase reliability and objectivity [34] and is partially viewed as an objective measure. Although it has to be noted that no rotation can be seen when conducting 2D measures [27]. Investigators who conduct presented screening tests without any technological aid should be experienced in monitoring movements in general and receive specific training within the selected testing method. This enhances inter-rater reliability as well as intra-rater reliability [12] [34] [35]. In order to increase quality criteria and the accuracy of measurement the inspection of the athlete should be carried out by using different points of view-ideally in frontal and sagittal plane as different deviations in movement quality can be viewed from different angles [20].

\section{Outlook}

Further studies on the validation of quality criteria under the use of objective 
and technical measures are essentially needed in order to apply subjective measures reliably.

In general subjective measures within the assessment of movement quality should be used in combination with further tests like strength-, flexibility- and agility testing as well as EMG-measurements. All of these methods are of particular importance for matching the abilities of the injured athlete with the requirements in high performance sports and to eliminate risk factors which could lead to further injuries. The tests should be incorporated in all different stages of rehabilitation to ensure a safe RTP. Only a few basic approaches on an ideal integration of these measures exist up to now [36] [37]. Further studies are necessary. Especially the assessment of movement quality as a measurement of injury risk should not only be done after injury. Regular pre-injury screenings assessing the movement quality should be carried out to prevent injuries.

\section{Acknowledgements}

The authors thank Claas Lendt for his efforts and help preparing this publication.

\section{References}

[1] Hagglund, M., Walden, M. and Ekstrand, J. (2006) Previous Injury as a Risk Factor for Injury in Elite Football: A Prospective Study over Two Consecutive Seasons. British Journal of Sports Medicine, 40, 767-772.

https://doi.org/10.1136/bjsm.2006.026609

[2] Barber-Westin, S.D. and Noyes, F.R. (2011) Objective Criteria for Return to Athletics after Anterior Cruciate Ligament Reconstruction and Subsequent Reinjury Rates: A Systematic Review. The Physician and Sportsmedicine, 39, 100-110. https://doi.org/10.3810/psm.2011.09.1926

[3] Fulton, J., Wright, K., Kelly, M., Zebrosky, B., Zanis, M., Drvol, C. and Butler, R. (2014) Injury Risk Is Altered by Previous Injury: A Systematic Review of the Literature and Presentation of Causative Neuromuscular Factors. International Journal of Sports Physical Therapy, 9, 583-595.

[4] Ardern, C.L., Taylor, N.F., Feller, J.A. and Webster, K.E. (2014) Fifty-Five per Cent Return to Competitive Sport Following Anterior Cruciate Ligament Reconstruction Surgery: An Updated Systematic Re-View and Meta-Analysis including Aspects of Physical Functioning and Contextual Factors. British Journal of Sports Medicine, 48, 1543-1552. https://doi.org/10.1136/bjsports-2013-093398

[5] Bizzini, M. and Silvers, H.J. (2014) Return to Competitive Football after Major Knee Surgery: More Questions than Answers? Journal of Sports Sciences, 32, 1209-1216. https://doi.org/10.1080/02640414.2014.909603

[6] Paterno, M.V., Schmitt, L.C., Ford, K.R., Rauh, M.J., Myer, G.D., Huang, B. and Hewett, T.E. (2010) Biomechanical Measures during Landing and Postural Stability Predict Second Anterior Cruciate Ligament Injury after Anterior Cruciate Ligament Reconstruction and Return to Sport. The American Journal of Sports Medicine, 38, 1968-1978. https://doi.org/10.1177/0363546510376053

[7] Barber-Westin, S.D. and Noyes, F.R. (2011) Factors Used to Determine Return to Unrestricted Sports Activities after Anterior Cruciate Ligament Reconstruction. Arthroscopy, 27, 1697-1705. https://doi.org/10.1016/j.arthro.2011.09.009 
[8] Myer, G.D., Ford, K.R. and Hewett, T.E. (2011) New Method to Identify Athletes at High Risk of ACL Injury Using Clinic-Based Measurements and Freeware Computer Analysis. British Journal of Sports Medicine, 45, 238-244. https://doi.org/10.1136/bjsm.2010.072843

[9] Powers, C.M. (2010) The Influence of Abnormal Hip Mechanics on Knee Injury: A Biomechanical Perspective. Journal of Orthopaedic \& Sports Physical Therapy, 40, 42-51. https://doi.org/10.2519/jospt.2010.3337

[10] McGill, S.M., Andersen, J.T. and Horne, A.D. (2012) Predicting Performance and Injury Resilience from Movement Quality and Fitness Scores in a Basketball Team over 2 Years. Journal of Strength \& Conditioning Research, 26, 1731-1739. https://doi.org/10.1519/JSC.0b013e3182576a76

[11] Warren, M., Smith, C.A. and Chimera, N.J. (2015) Association of the Functional Movement Screen with Injuries in Division I Athletes. Journal of Sport Rehabilitation, 24, 163-170. https://doi.org/10.1123/jsr.2013-0141

[12] Doyscher, R., Schütz, E. and Kraus, K. (2016) Evidenz des Functional Movement Screen im Leistungssport-Ein strukturierter Review mit eigenen Daten. Sports Orthopaedicsand Traumatology, 32, 4-13.

[13] Bonazza, N.A., Smuin, D., Onks, C.A., Silvis, M.L. and Dhawan, A. (2016) Reliability, Validity, and Injury Predictive Value of the Functional Movement Screen: A Systematic Review and Meta-Analysis. The American Journal of Sports Medicine, $45,725-732$.

[14] Moran, R.W., Schneiders, A.G., Major, K.M. and Sullivan, S.J. (2016) How Reliable Are Functional Movement Screening Scores? A Systematic Review of Rater Reliability. British Journal of Sports Medicine, 50, 527-536. https://doi.org/10.1136/bjsports-2015-094913

[15] Cuchna, J.W., Hoch, M.C. and Hoch, J.M. (2016) The Interrater and Intrarater Reliability of the Functional Movement Screen: A Systematic Review with $\mathrm{Me}$ ta-Analysis. Physical Therapy in Sport, 19, 57-65.

[16] McKeown, I., Taylor-McKeowm, K., Woods, C. and Ball, N. (2014) Athletic Ability Assessment: A Movement Assessment Protocol for Athletes. The International Journal of Sports Physical Therapy, 9, 862-873.

[17] Onate, J., Cortes, N., Welch, C. and van Lunen, B.L. (2010) Expert versus Novice Interrater Reliability and Criterion Validity of the Landing Error Scoring System. Journal of Sport Rehabilitation, 19, 41-56. https://doi.org/10.1123/jsr.19.1.41

[18] Smith, H.C., Johnson, R.J., Shultz, S.J., Tourville, T., Holterman, L.A., Slauterbeck, J., et al. (2012) A Prospective Evaluation of the Landing Error Scoring System (LESS) as a Screening Tool for Anterior Cruciate Ligament Injury Risk. The American Journal of Sports Medicine, 40, 521-526.

https://doi.org/10.1177/0363546511429776

[19] Padua, D.A., DiStefano, L.J., Beutler, A.I., de La Motte, S.J., DiStefano, M.J. and Marshall, S.W. (2015) The Landing Error Scoring System as a Screening Tool for an Anterior Cruciate Ligament In-Jury-Prevention Program in Elite-Youth Soccer Athletes. Journal of Athletic Training, 50, 589-595.

https://doi.org/10.4085/1062-6050-50.1.10

[20] O’Connor, M.L. (2015) The Development of the Single-Leg Landing Error Scoring System (SL-LESS) for Lower Extremity Movement Screening. Master Thesis, University of Wisconsin-Milwaukee, Milwaukee.

[21] Padua, D.A., Boling, M.C., DiStefano, L.J., Onate, J.A., Beutler, A.I. and Marshall, S.W. (2011) Reliability of the Landing Error Scoring System-Real Time, a Clinical 
Assessment Tool of Jump-Landing Biomechanics. Journal of Sport Rehabilitation, 20, 145-156. https://doi.org/10.1123/jsr.20.2.145

[22] Herrington, L. and Munro, A. (2014) A Preliminary Investigation to Establish the Criterion Validity of a Qualitative Scoring System of Limb Alignment during Single Leg Squat and Landing. Journal of Exercise, Sports \& Orthopedics, 1, 1-6.

[23] Almangoush, A., Herrington, L. and Jones, R. (2014) A Preliminary Reliability Study of a Qualitative Scoring System of Limb Alignment during Single Leg Squat. Physical Therapy and Rehabilitation, 1, 2.

[24] Myer, G.D., Brent, J.L., Ford, K.R. and Hewett, T.E. (2011) Real-Time Assessment and Neuromuscular Training Feedback Techniques to Prevent ACL Injury in Female Athletes. Strength \& Conditioning Journal, 33, 21-35. https://doi.org/10.1519/SSC.0b013e318213afa8

[25] Read, P.J., Oliver, J.L., Ste Croix, M.B.A. de, Myer, G.D. and Lloyd, R.S. (2016) Reliability of the Tuck Jump Injury Risk Screening Assessment in Elite Male Youth Soccer Players. The Journal of Strength \& Conditioning Research, 30, 1510-1516. https://doi.org/10.1519/JSC.0000000000001260

[26] Herrington, L., Myer, G.D. and Munro, A. (2013) Intra and Inter-Tester Reliability of the Tuck Jump Assessment. Physical Therapy in Sport, 14, 152-155.

[27] Garrison, C.J., Shanley, E., Thigpen, C., Geary, R., Osler, M. and DelGiorno, J. (2012) The Reliability of the Vail Sport Test as a Measure of Physical Performance following Anterior Cruciate Ligament Reconstruction. International Journal of Sports Physical Therapy, 7, 20-30.

[28] Jöllenbeck, T., Freiwald, J., Dann, K., Gokeler, A., Zantop, T., Seil, R. and Miltner, O. (2013) Prävention von Verletzungen: Review $\mathrm{zu}$ Strategien und Evidenz. [Prevention of Injuries: Review on Strategies and Evidence.] Sports Orthopaedics and Traumatology, 29, 13-21.

[29] Weiss, K. and Whatman, C. (2015) Biomechanics Associated with Patellofemoral Pain and ACL Injuries in Sports. Sports Medicine, 45, 1325-1337. https://doi.org/10.1007/s40279-015-0353-4

[30] Klugman, M.F., Brent, J.L., Myer, G.D., Ford, K.R. and Hewett, T.E. (2011) Does an In-Season Only Neuromuscular Training Protocol Reduce Deficits Quantified by the Tuck Jump Assessment? Clinics in Sports Medicine, 30, 825-840.

[31] Kokmeyer, D. and Hodge, J. (2013) Rehabilitation of Postoperative Hip. In: Nho, S., Leunig, M., Kelly, B., Bedi, A. and Larson, C., Eds., Hip Arthroscopy and Hip Joint Preservation Surgery, Springer, New York, 1-21.

[32] Pierce, C.M., Laprade, R.F., Wahoff, M., O’Brien, L. and Philippon, M.J. (2013) Ice Hockey Goal-Tender Rehabilitation, Including On-Ice Progression, after Arthroscopic Hip Surgery for Femoroacetabular Impingement. Journal of Orthopaedic \& Sports Physical Therapy, 43, 129-141. https://doi.org/10.2519/jospt.2013.4430

[33] Wahoff, M., Dischiavi, S., Hodge, J. and Pharez, J.D. (2014) Rehabilitation after Labral Repair and Femoroacetabular Decompression: Criteria-Based Progression through the Return to Sport Phase. International Journal of Sports Physical Therapy, 9, 813-826.

[34] Shultz, R., Anderson, S.C., Matheson, G.O., Marcello, B. and Besier, T. (2013) Test-Retest and Interrater Reliability of the Functional Movement Screen. Journal of Athletic Training, 48, 331-336. https://doi.org/10.4085/1062-6050-48.2.11

[35] Whatman, C., Hing, W. and Hume, P. (2012) Physiotherapist Agreement When Visually Rating Movement Quality during Lower Extremity Functional Screening 
Tests. Physical Therapy in Sport, 13, 87-96.

[36] Gokeler, A., Welling, W., Zaffagnini, S., Seil, R. and Padua, D. (2016) Development of a Test Battery to Enhance Decision Making in Return to Sports after Anterior Cruciate Ligament Reconstruction. Sports Orthopaedics and Traumatology, 32, 195-196.

[37] Keller, M., Kurz, E., Schmidtlein, O., Welsch, G. and Anders, C. (2016) Interdisziplinäre Beurteilungskriterien für die Rehabilitation nach Verletzungen an der unteren Extremität: Ein funktionsbasierter Return to Activity Algorithmus. [Interdisciplinary Assessment Criteria for Rehabilitation after Injuries of the Lower Extremity: A Function-Based Return-to-Activity Algorithm.] Sportverletz Sportschaden, 30, 38-49. https://doi.org/10.1055/s-0042-100966

Submit or recommend next manuscript to SCIRP and we will provide best service for you:

Accepting pre-submission inquiries through Email, Facebook, LinkedIn, Twitter, etc. A wide selection of journals (inclusive of 9 subjects, more than 200 journals) Providing 24-hour high-quality service User-friendly online submission system Fair and swift peer-review system Efficient typesetting and proofreading procedure Display of the result of downloads and visits, as well as the number of cited articles Maximum dissemination of your research work

Submit your manuscript at: http://papersubmission.scirp.org/ Or contact health@scirp.org 